\title{
Results of tadalafil treatment in patients following an open nerve-sparing radical prostatectomy
}

\author{
Erkan Hirik $^{1}$, Aliseydi Bozkurt ${ }^{1}$, Mehmet Karabakan ${ }^{1}$, Özkan Onuk ${ }^{2}$, Mustafa Bahadır Can Balcı ${ }^{2}$, \\ Memduh Aydın ${ }^{2}$, Murat Çakan ${ }^{1}$, Barış Nuhoğlu ${ }^{1}$ \\ ${ }^{1}$ Erzincan University Mengücek Gazi Education and Research Hospital, Urology Clinic, Turkey; \\ ${ }^{2}$ Gaziosmanpaşa Taksim Education and Research Hospital, Urology Clinic, Turkey.
}

\begin{abstract}
Summary Purpose: To evaluate the effect of postoperatively administering a low daily dose of tadalafil on the erectile function of patients who underwent a nerve-sparing radical prostatectomy(NSRP) due to localized prostate cancer (PCa).

Materials and Methods: Of 138 patients, who underwent NSRP due to PCa between 2012 and 2014, 55 patients who had not had pre-operative erectile dysfunction (ED) were included in the study. The mean age of the patients was 64 (54-72). On the 15th day after surgery, after ultrasound evaluation, all 55 patients started on a daily dose of $5 \mathrm{mg}$ tadalafil that was continued for 2.5 months. The erectile function of patients was evaluated pre-operatively, post-operatively, and at the $3^{\text {rd }}$ and $6^{\text {th }}$ month after surgery using the International Index of Erectile Function (IIEF-5) test. None of the patients was treated with hormonal therapy or radiotherapy before or after surgery.

Results: Three patients were excluded from the study due to the adverse effects of tadalafil and two patients elected to discontinue the treatment. Of the remaining 50 patients whose pre-operative erectile function had been found normal, at 3 months after surgery, 36 (72\%) had normal erectile function; of the remaining patients in the study six $(12 \%)$ presented with mild, two (4\%) with moderate, and six (12\%) with severe ED. Six months after surgery, 35 patients (70\%) had normal erectile function while seven (14\%) had mild, three (6\%) moderate and five (10\%) severe ED. There was no statistically significant difference between the results obtained at the 3rd and 6thmonth follow-up ( $p>0.05)$. Three patients reported adverse effects with tadalafil including flushes in 2 (3.6\%) and a headache in 1 (1.8\%).

Conclusions: The administration of a $5 \mathrm{mg}$ post-operative dose of tadalafil to patients that had undergone a bilateral NSRP was found to have a positive effect on the recovery and maintenance of erectile function. However, there is still a need to investigate a larger series of cases.
\end{abstract}

KEY WORDS: Radical prostatectomy; Tadalafil; Erectile function. Submitted 28 July 2015; Accepted 13 October 2015

\section{INTRODUCTION}

Prostate cancer (PCa) is the most frequent type of cancer in men aged over 50 and the second most common reason for cancer-related deaths (1). For cases in which there is a life expectancy of more than 10 years, radical prostatectomy (RP) is a gold standard treatment for organ-confined PCa (2). Erectile dysfunction (ED) developing after an RP (ED) is one of the most significant problems that affect the quality of life (3). The definition of anatomic RP and the development of a better understanding of the neuroanatomy of prostate in the last 20 years have resulted in a significant improvement in retaining sexual functions after RP, however, the prevalence of post-operative ED is still above $50 \%(4,5)$. To eliminate the negative outcomes of the treatment for PCa, 'ED treatment and penile rehabilitation after RP' has become a widely investigated topic in preclinical and clinical studies (6). Even though the first-line therapy for ED is phosphodiesterase type 5 (PDE5) inhibitors, there is still not a standard treatment program. In this study, we evaluated the safety and effects of a low-dose of postoperative tadalafil on the erectile functions of patients who had undergone an NSRP due to localized PCa.

\section{MATERIAL AND METHOdS}

Of 138 cases that were treated with NSRP due to PCa between 2012 and 2014, 55 patients, who had not had pre-operative erectile dysfunction (ED) and had undergone a bilateral NSRP, were included in the study. The erectile function of the patients was evaluated pre-operatively and post-operatively by the International Index of Erectile Function (IIEF-5) test. An open RP was performed using the classical technique and nerve-sparing approach. Following an ultrasound examination on the post-operative $15^{\text {th }}$ day, all patients were prescribed a daily dose of 5 mg tadalafil to be continued for 10 weeks. The erectile functions of patients were evaluated at the $3^{\text {rd }}$ and $6^{\text {th }}$ postoperative month. Potency was defined as the ability to achieve unassisted sexual intercourse through vaginal penetration. None of the patients received hormone therapy or radiotherapy before or after surgery. In addition, to exclude the possibility of androgen insensitivity syndrome, the pre-operative serum total testosterone and body mass index (BMI) of the patients were measured.

\section{RESULTS}

The mean age of patients was 64 years (54-72) and the mean BMI was calculated as 24.3 (18.1-33.4). Table 1 
Table 1.

Demographic information on patients.

\begin{tabular}{|lc|}
\hline Age & $64(54-72)$ \\
\hline Body Mass Index (BMI) & $24.3(18.1-33.4)$ \\
\hline Comorbidity & $8(16 \%)$ \\
DM & $32(64 \%)$ \\
HT & $3(6 \%)$ \\
Hepatitis & $7.2(2.5-18)$ \\
PSA & \\
Biopsy Gleason Score & $31(62 \%)$ \\
$4-6$ & $17(34 \%)$ \\
7 & $2(4 \%)$ \\
8 & \\
\hline
\end{tabular}

Table 2.

Erectile function after prescribing $5 \mathrm{mg}$ tadalafil daily to patients without pre-operative ED who underwent bilateral NSRP.

\begin{tabular}{|lcc|}
\hline Erectile function & $\begin{array}{c}\text { 3-month post-operative } \\
(\mathbf{n}=\mathbf{5 0})\end{array}$ & $\begin{array}{c}\text { 6-month post-operative } \\
(\mathbf{n}=\mathbf{5 0})\end{array}$ \\
\hline Normal & $36(72 \%)$ & $35(70 \%)$ \\
Mild ED & $6(12 \%)$ & $7(14 \%)$ \\
Moderate ED & $2(4 \%)$ & $3(6 \%)$ \\
Severe ED & $6(12 \%)$ & $5(10 \%)$ \\
\hline
\end{tabular}

presents the demographic information on patients. Of the 55 patients who had not had ED prior to the operation and had undergone a bilateral NSRP, three patients were excluded from the study due to the adverse effect of tadalafil and two patients discontinued the treatment. Of the remaining 50 patients whose pre-operative erectile function was found to be normal, at 3-month post-operative follow up, $36(72 \%)$ had normal erectile function while six (12\%) presented with mild, two (4\%) with moderate, and six (12\%) with severe ED. At 6 month follow up after surgery, 35 patients (70\%) had normal erectile function while seven (14\%) had mild, three (6\%) moderate and five (10\%) severe ED. There was no statistically significant difference between the results obtained at 3- and 6- month follow-up ( $p>0.05)$. Three patients reported adverse effects with tadalafil; including flushes in two (3.6\%) and headache in one (1.8\%).

\section{Discussion}

Our results show that most patients (72\%) who were treated with $5 \mathrm{mg}$ tadalafil daily following a bilateral NSRP had normal erectile function at 3-month postoperative follow up while severe ED was observed in $12 \%$ of the patients. Similar results were obtained from the evaluation at 6-month post-operative follow up. Considering the $50 \%$ prevalence of ED reported in the literature in patients who received no post-operative treatment, the results of the current study indicate that tadalafil treatment after RP contributes to the early recovery of erection and the retention of this function even after 6 months $(24,25)$.

The development of ED after RP has been reported to be the result of an injury to cavernous nerves and pudendal arteries (11-13). Factors that are known to have an effect on the post-operative erectile function of patients are age, pre-operative potency, and surgery with nerve sparing intent. When surgical modalities are compared, no significant difference has been observed in the prevalence of ED between the results of laparoscopic and open NSRP whereas robotic surgery has been found to produce much better post-operative results compared to the other two methods (13).

Most patients who are diagnosed with localized PCa are in the advanced age group. Diseases that have already developed or will possibly develop due to old age increase the process of ED (14). Since after RP it takes a long time to recover normal erection function there is a need to seek for a treatment option that will shorten this period. In the literature, the first study that monitored the results of patients after NSRP for more than 5 years was conducted by Zippe et al. This study showed the importance of ED treatment but it has been commented that the process is like a marathon race. According to the last report of Zippe et al. after a follow-up of $6.4 \pm 1.8$ years, only $50 \%$ of the patients were sexually active, and of these patients, only $23 \%$ had a natural normal erection function with the remaining $77 \%$ needing oral or other treatments (7).

Many papers have reported on various post RP treatments; for example, PDE5 inhibitors induce cGMP accumulation in corporal smooth muscles resulting in the relaxation of these muscles. Goldstein et al. (15) reported a success rate of $43 \%$ after the use of PDE5 inhibitors in patients who had undergone RP. Raina et al. (16) showed that bilateral NSRP produced better results than unilateral NSRP and other treatments that do not involve the use of nerve-sparing technique. In experimental studies, PDE5 inhibitors have been reported to be effective in preventing ED due to cavernous nerve trauma (17). Kovanecz et al. investigated the effect of sildenafil on rats who underwent a cavernosal nerve resection and found that the treatment group had significantly better intracavernosal pressure/mean arterial pressure (ICP/MAP); the cell content of smooth muscles and endothelial factors were retained and apoptosis was reduced; there was also an improvement in venous leak in the long term (17). Similarly, studies conducted with vardenafil and tadalafil reported that the use of these drugs prevent corporal fibrosis, reduce collagen production and retain the content of smooth muscles (18-20). PDE5 inhibitors have been found to be effective in recovering and retaining the erectile function in patients after NSRP (21-23). The use of PDE-5 inhibitors for erection rehabilitation after RP has recently become a widely discussed topic. The reason for using these drugs is to make it easy for the patient in the recovery period to have sexual intercourse, also, as much as possible, reduce cavernosal hypoxia and protect the penis from apoptosis and cavernosal fibrosis. Since these drugs also increase corporal oxygenation, they will ease night-time erections and protect the basal functions of corpus cavernosum (8). Raina et al. reported that starting the treatment of PDE5 inhibitors earlier than 6 months after surgery significantly improves the response to PDE5, and therefore, the authors suggested the use of sildenafil post-operatively for a period of 3 to 6 months (9). As the RP-related neuropraxia heals over 
time, cavernosal smooth muscles respond better to PDE5 inhibitors.

This is due to the increase in the nitric oxide (NO) released by the nerve that starts to heal. Since recovery is dependent on time, even when the response to sildenafil is lower within the first 6 months after surgery, over time it starts improving (10). Similarly, in the current study, treatment with a daily $5 \mathrm{mg}$ dose of tadalafil for 10 weeks was found to be efficient. However, there is a need for further studies that will comparatively evaluate larger series of cases over a longer period of time.

\section{Conclusions}

A $5 \mathrm{mg}$ post-operative dose of tadalafil was found to have a positive effect on patients that had undergone a bilateral NSRP in terms of the recovery and maintenance of erectile function. However, there is still a need to conduct studies on larger series of cases and including a control group for comparative purposes.

\section{REFERENCES}

1. Landis SH, Murray T, Bolden S, Wingo PA. Canser statistics, 1999, CA Cancer J Clin. 1999; 49:8-31.

2. Partin AW, Mangold LA, Lamm DM, et al. Contemporary update of prostate cancer staging nomograms (PartinTables) for the new millennium. Urology. 2001; 58:843-8.

3. Burnett AL, Aus G, Canby-Hagino ED, et al. Erectile function outcome reporting after clinically localized prostate cancer treatment. J Urol. 2007; 178:597-601.

4. Walsh PC, Donker PJ.Impotence following radical prostatectomy:insight into etiology and prevention. J Urol. 1982; 128:492-7.

5. Talcott JA, Rieker P, Propert KJ, Clark JA, et al. Patient-reported impotence and incontinence after nerve-sparingradical prostatectomy. J Natl Cancer Inst. 1997; 89:1117-23.

6. Montorsi F, Briganti A, Salonia A, et al: Current and future strategies for preventing and managing erectile dysfunction following radical prostatectomy. Eur Urol., 2004; 45:123-33.

7. Zippe C, Nandipati K, Agarwal A, et al. Sexual dysfunction after pelvic surgery. Int J Impot Res. 2006; 18:1-18.

8. Montorsi F, Briganti A, Salonia A, et al. Current and future strategies for preventing and managing erectile dysfunction following radical prostatectomy review. Eur Urol. 2004; 45:123-33.

9. Raina R, Lakin MM, Agarwal A, et al: Efficacy and factors associated with successful outcome of sildenafil citrate use for erectile dysfunction after radical prostatectomy Urology. 2004; 63:960-966.

10. Padma-Nathan H. PDE-5 Inhibitor Therapy for Erectile Dysfunction Secondary to Nerve-Sparing Radical Retropubic Prostatectomy. Rev Urol. 2005; 7 (Suppl 2): 33-8.

11. Carrier S, Zvara P, Nunes L, et al. Regeneration of nitric oxide synthase containing nerves after cavernous nerveneurotomy in the rat. J Urol. 1995; 153:1722-7.

12. Zippe CD, Pahlajani G. Penile rehabilitation following radical prostatectomy: role of early intervention and chronic therapy. Urol ClinNorth Am 2007; 34: 601-18.

13. Akbal C, Simsek F. Radikal prostatektomi sonrast erektil disfonksiyonönlenebilir mi? Cerrahi ve medikal alternatifler var $\mathrm{ml}$ ? Üroonkoloji Bülteni 112-6.
14. Martin-Morales A, Sanchez-Cruz JJ, Saenz de Tejada I, et al. Prevalence and independent risk factors for erectile dysfunction in Spain: results of theEpidemiologia de la Disfuncion Erectil Masculina Study. J Urol. 2001; 166:569-75.

15. Goldstein I, Lue TF, Padma-Nathan H, et al. Oral sildenafil in the treatment of erectile dysfunction. SildenafilStudy Group. N Engl J Med .1998; 338:1397-404.

16. Raina R, Lakin MM, Agarwal A, et al. Long-term effect of sildenafil citrate on erectile dysfunction after radical prostatectomy: 3year follow-up. Urology. 2003; 62:110-5.

17. Kovanecz I, Rambhatla A, Ferrini M, et al. Long-term continuous sildenafil treatment ameliorates corporalveno-occlusive dysfunction (CVOD) induced by cavernosal nerve resection in rats. Int $J$ Impot Res. 2008; 20:202-12.

18. Ferrini MG, Davila HH, Kovanecz I, et al. Vardenafil prevents fibrosis and loss of corporal smoothmuscle that occurs after bilateral cavernosal nerve resection in therat. Urology. 2006; 68:429-35.

19. Kovanecz I, Rambhatla A, Ferrini MG, et al. Chronic daily tadalafil prevents the corporal fibrosis and venoocclusive dysfunction that occurs after cavernosal nerve resection. BJU Int. 2008; 101:203-10.

20. Lysiak JJ, Yang SK, Klausner AP, et al. Tadalafil increases Akt and extracellular signal-regulated kinase 1/2activation, and prevents apoptotic cell death in the penis followingdenervation. J Urol. 2008; 179:779-85.

21. Nakano Y, Miyake H, Chiba K, Fujisawa M. Impact of penile rehabilitation with low-dose vardenafil on recovery of erectile function in Japanese men following nerve-sparing radical prostatectomy. Asian J Androl. 2014; 16:892-6.

22. Gandaglia G, Gallina A, Suardi N, et al. Preoperative erectile function is the only predictor of the use of a high number of phosphodiesterase type-5 inhibitors after bilateral nerve-sparing radical prostatectomy.nt J Impot Res. 2014; 26:2014.

23. Cathala N1, Mombet A, Sanchez-Salas R, et al. Evaluation of erectile function after laparoscopic radical prostatectomy in a single center. Can J Urol. 2012; 19:6328-35.

24. Stolzenburg JU, Graefen M, Kriegel C, et al. Effect of surgical approach on erectile function recovery following bilateral nervesparing radical prostatectomy: an evaluation utilising data from a randomised, double-blind, double-dummy multicentre trial of tadalafil vs placebo. BJU Int. 2015; 116:241-51.

25. Moncada I1, de Bethencourt FR, Lledó-García E, et al. Effects of tadalafil once daily or on demand versus placebo on time to recovery of erectile function in patients after bilateral nerve-sparing radical prostatectomy. World J Urol. 2015; 33:1031-8.

Correspondence
Erkan Hirik
ehirik@gmail.com
Aliseydi Bozkurt
Mehmet Karabakan
Murat Çakan
Barıs Nuhoğlu
Erzincan University Mengücek Gazi Education and Research Hospital,
Urology Clinic, Turkey

Özkan Onuk, Mustafa Bahadir Can Balcl, Memduh Aydin, Gaziosmanpaşa Taksim Education and Research Hospital, Urology Clinic, Turkey 